\title{
Melting Separation Process of High Chromium Vanadium-bearing Titanomagnetite Metallized Pellet and its Optimization by Multi- Index Synthetic Weighted Scoring Method
}

\author{
Jue TANG, Mansheng CHU, ${ }^{*}$ Cong FENG, Feng LI, Yating TANG and Zhenggen LIU \\ Institute of Ferrous Metallurgy, Northeastern University, 3-11 Wenhua Road, Heping District, Shenyang, 110819 China. \\ (Received on December 7, 2016; accepted on March 21, 2017; J-STAGE Advance published date: May \\ 26, 2017)
}

\begin{abstract}
Based on the gas-based direct reduction followed by melting separation process, the melting separation process of high chromium vanadium-bearing titanomagnetite metallized pellet and its optimization by multi-index synthetic weighted scoring method are studied in the present work. The optimal melting separation parameters include a melting temperature of $1650^{\circ} \mathrm{C}$, a melting time of $45 \mathrm{~min}$, and a basicity of 1.10. Under these conditions, the recoveries of $\mathrm{Fe}, \mathrm{V}, \mathrm{Cr}$, and $\mathrm{TiO}_{2}$ reach $99.87 \%, 98.26 \%, 95.32 \%$, and 95.04\% respectively; the mass fraction of $\mathrm{Fe}, \mathrm{V}, \mathrm{Cr}$, and $\mathrm{TiO}_{2}$ are $94.16 \%, 0.94 \%, 0.76 \%$, and $38.21 \%$ respectively. The basicity has the strongest effect and its effect on the melting separation kinetic is more significant than thermodynamic. As increased basicity from 0.6 to 1.1, the slag viscosity decreases and surface tension increases, which are both attributed to smooth melting separation and improved indexes. But further increasing basicity to 1.2, the amount of $\mathrm{CaTiO}_{3}$ and slag melting point increase, and the slag amount is relatively excessive, then all the melting separation indexes decrease instead. The melting separation contains four key behaviors: Fe-C melt formation and $\mathrm{Fe}(\mathrm{I})$ generation; slag melting initiation and slag(I) generation; small iron droplets formation and start of iron-slag separation; continuous aggregation and growth of iron and accomplishment of iron-slag separation. The iron aggregation and growth should go through iron crystal nucleus formation, reaction interface formation and enlargement, and subsequent reaction interface decrease.
\end{abstract}

KEY WORDS: high-chromium vanadium-bearing titanomagnetite; melting separation; recovery; optimization; multi-index synthetic weighted scoring method.

\section{Introduction}

Vanadium-bearing titanomagnetite (VT) is a polymetallic intergrowth iron ore that owns a wide distribution throughout the world such as Russia, China, North Africa, and America etc. ${ }^{1)}$ In VT, there are various valuable elements including iron, titanium, vanadium, and chromium which are typical strategic resources due to its extensive application in metallurgy, chemical industry, and aerospace etc. ${ }^{2-4)}$ Based on the mass fraction of $\mathrm{Cr}_{2} \mathrm{O}_{3}$, VT is classified into two categories: ordinary VT and high chromium vanadiumbearing titanomagnetite (HCVT), and HCVT has a higher comprehensive utilization value. ${ }^{2)}$

At present, VT is smelt in blast furnace (BF) but the recovery rate of $\mathrm{Fe}, \mathrm{V}$, and $\mathrm{TiO}_{2}$ is only reach $70 \%, 39 \%$ and $13 \%$ respectively. ${ }^{5-7)}$ Recently, the technology of direct reduction followed by melting separation applying to dispose special metallurgical resources has attracted increasing attention. ${ }^{8-11)}$ Jun et al. ${ }^{8)}$ studied the carbothermal reductionmelting separation process for copper slag. In Guang et

\footnotetext{
* Corresponding author: E-mail: chums@smm.neu.edu.cn DOI: http://dx.doi.org/10.2355/isijinternational.ISIJINT-2016-714
}

al.'s ${ }^{9)}$ work, both the boron-bearing nugget and boron-rich slag were obtained from ludwigite through carbon bearing pellet reduction-melting technology. No matter BF process and present coal based direct reduction-melting separation process, it should be noted that the reduction by carbon is relatively slow and consumes large amounts of energy. But the gas-based reduction seems to be a novel and effective method to process VT due to its rapid reduction and clean production. ${ }^{12-14)}$

The multi-index synthetic weighted scoring method is one of scientific evaluation methods used to optimize parameters for multi-index system. It contains three parts: (1) the weight of each factor is determined by its importance for the whole test; (2) the multi-index results is changed to a final single result that is synthetic scoring value; (3) the synthetic scoring value is analyzed by the normal single index analysis method. Here, the weight of each factor is a key point. To ensure a true and effective result, both the subjective cognition (experience) on the factor importance by tester and the objective information from test results are considered in this method. Finally the optimization model of synthetic scoring value is established based on the optimization theory, and its exact solution is given. ${ }^{15,16)}$ So the 
analyses are reasonable and credible, and it has been widely applied in lots of fields such as agriculture, pharmacy, and manufacturing industry. ${ }^{18,19)}$

Due to the previously discussed low recovery rate, high energy consumption, and slag pollution by solid reductant during $\mathrm{BF}$ or coal-based direct process, a new gas based reduction-melting process for HCVT has been proposed and researched by authors' team. ${ }^{2,20,21)}$ From the previous work by author, ${ }^{21)}$ it has been proved that the iron containing $\mathrm{V}$ and $\mathrm{Cr}$ together with the slag bearing Ti can be obtained by the new process. Also, the effect rules of key parameters on high chromium vanadium-bearing titanomagnetite metallized pellet (HCVTMP) melting separation are investigated by the single index test. However, for a multi-index evaluation system, the optimal parameters obtained from single index test are not enough and imprecise, the scientific test should be designed and carried out. Subsequently, the proper and credible data analysis method is also distinctly necessary. In addition, till now there is no clear description on the detailed HCVTMP melting separation process, such as the behaviors on the aggregation, growth, and separation of reduced metals. Therefore in this work, firstly the orthogonal test is conducted and the key HCVTMP melting separation parameters are optimized by multi-index synthetic weighted scoring method. And then the detailed process of HCVTMP melting separation is discussed with the help of in-situ confocal laser-scanning microscope (CLSM) observation.

\section{Experimental}

The HCVTMP with a metallization rate of about $95 \%$ obtained from gas-based furnace direct reduction is applied in the work and the chemical composition analyzed by ICPOES is listed in Table 1. The amount of HCVTMP sample is $100 \mathrm{~g}$. The analytically pure activated carbon, $\mathrm{CaO}$, and $\mathrm{CaF}_{2}$ with the particle size less than $0.074 \mathrm{~mm}$ are used in the work. The $\mathrm{C} / \mathrm{O}$ is defined as the mole ratio of carbon to reducible oxygen in iron, vanadium, chromium, and titanium oxides. According to the early work by author, ${ }^{21)}$ the amount of carbon in the work is based on $\mathrm{C} / \mathrm{O}$ of 1.20 for sufficient deep reduction and carburization. The basicity defined as $\mathrm{CaO} / \mathrm{SiO}_{2}$ is the mass fraction ratio of $\mathrm{CaO}$ to $\mathrm{SiO}_{2}$ in raw material. Through adjusting the mass of $\mathrm{CaO}$, a series of basicity in designed tests is obtained. Taking the basicity of 1.10 as an example, if the basicity is adjusted to 1.10 , the mass of addition $\mathrm{CaO}$ is $3.08 \mathrm{~g}((0.34+\mathrm{x}) / 3.11=1.10$, $\mathrm{x}=3.08 \mathrm{~g})$. And considering the slag with good fluidity and the erosion to brusque based on the early work by author, ${ }^{21)}$ the addition of $\mathrm{CaF}_{2}$ in the work is $2 \%$ (100 g HCVTMP, $2 \mathrm{~g} \mathrm{CaF}_{2}$ ).

The melting separation of HCVTMP is carried out in a medium frequency induction furnace (XZ-40B), and the sketch map is shown as Fig. 1. The temperature is measured by an infrared thermometer (DT-8869h) with a measure range of $-50 \sim 2200^{\circ} \mathrm{C}$ and a accuracy of $0.1^{\circ} \mathrm{C}$. The HCVTMP is crushed to below $1 \mathrm{~mm}$. Then the materials including powder samples, activated carbon, $\mathrm{CaO}$, and $\mathrm{CaF}_{2}$ are weighted, mixed homogeneously, and loaded in a high pure graphite crucible. Next, the crucible is placed in the effective temperature section of furnace and heated at
Table 1. Chemical composition of HCVTMP (wt $\%$ ).

\begin{tabular}{ccccccccc}
\hline $\mathrm{TFe}$ & $\mathrm{MFe}$ & $\mathrm{V}_{2} \mathrm{O}_{5}$ & $\mathrm{TiO}_{2}$ & $\mathrm{Cr}_{2} \mathrm{O}_{3}$ & $\mathrm{CaO}$ & $\mathrm{SiO}_{2}$ & $\mathrm{MgO}$ & $\mathrm{Al}_{2} \mathrm{O}_{3}$ \\
\hline 76.62 & 73.09 & 1.387 & 9.267 & 0.947 & 0.34 & 3.16 & 1.55 & 4.28 \\
\hline
\end{tabular}

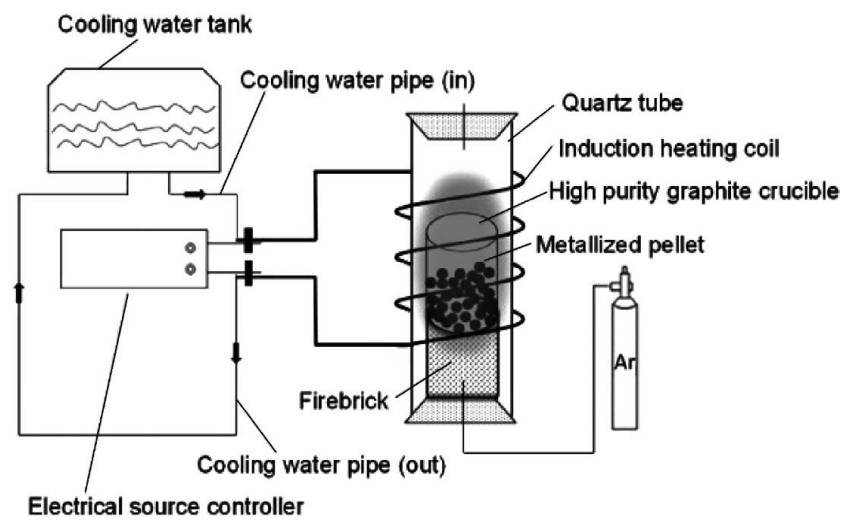

Fig. 1. Sketch map of medium frequency induction furnace.

high temperatures to realize the iron and slag separation. Argon atmosphere is keeping throughout the process. After melting separation, the furnace is shut down and the sample is rapidly cooled down in argon atmosphere. To ensure the significance of result, each test is checked for three times and the mean is taken as the final result.

The samples are analyzed by ICP-OES, SEM-EDS, and Factsage 7.0. In all calculations by Factsage, the system pressure is $1.01 \times 10^{5} \mathrm{~Pa}$, and the atmosphere is in Ar. And the equilibrium calculations are assumptive to explain the reactions and behaviors occurring during the experiment (non-equilibrium). The recovery rates of elements are calculated according to the mass balance and defined as:

$$
R_{\mathrm{TiO}_{2}}=\frac{W_{2} \times M_{S}}{W_{1} \times M_{P}} \times 100 \%
$$

Where, $R_{\mathrm{TiO}_{2}}$ is the recovery rate of $\mathrm{TiO}_{2}$ in slag, \%. $W_{1}$ and $W_{2}$ is the mass fraction of $\mathrm{TiO}_{2}$ in HCVTMP and slag respectively, \%. $M_{P}$ and $M_{s}$ is the mass of HCVTMP and slag respectively, $\mathrm{g}$.

$$
R_{x}=\frac{W_{4} \times M_{I}}{W_{3} \times M_{P}} \times 100 \%
$$

Where, $R_{x}$ is the recovery rates of elements (Fe, $\mathrm{V}$ and $\mathrm{Cr}$ ) in iron, \%. $W_{3}$ and $W_{4}$ is the mass fraction of element in HCVTMP and iron respectively, \%. $M_{I}$ is the mass of iron, $\mathrm{g}$.

CSLM is help for in-situ observation of HCVTMP melting separation behavior. A pressed pellet with the mixed material (crushed HCVTMP, $\mathrm{C}, \mathrm{CaO}$, and $\mathrm{CaF}_{2}$ ) is put in a platinum crucible and placed to the heating range just under the laser microscope. The inner chamber is sealed and purged with high purity Ar flow of $200 \mathrm{~mL} / \mathrm{min}$ during observation. The sample is rapidly heated up to $1050^{\circ} \mathrm{C}$ at the heating rate of $150^{\circ} \mathrm{C} / \mathrm{min}$, and then maintained for $30 \mathrm{~s}$ at $1050^{\circ} \mathrm{C}$. After stabilization, the sample is heated to $1600^{\circ} \mathrm{C}$ with the heating rate of $24^{\circ} \mathrm{C} / \mathrm{min}$, and then maintained for $40 \mathrm{~min}$ at $1600^{\circ} \mathrm{C}$. After the test, the sample is 
cooled down

\section{Results and Discussion}

\subsection{Orthogonal Test}

From the previous single index test, ${ }^{21)}$ the rough ranges of HCVTMP melting separation parameters are obtained: melting temperature (the set temperature of melting separation test ) is around $1625^{\circ} \mathrm{C}$, melting time (the holing time under the set melting temperature) is about $40-50 \mathrm{~min}$, and basicity $\left(\mathrm{CaO} / \mathrm{SiO}_{2}\right)$ is approximately kept at 1.10 . But for a multi-index evaluation system, the optimal parameters gotten from single index test are not enough and imprecise, the scientific test should be designed and carried out. So based on these results, the scheme of orthogonal test is detailed in Table 2. Three key process factors and three varying levels are used, including a melting temperature of $1600-1650^{\circ} \mathrm{C}$, a melting time of $45-55 \mathrm{~min}$, and a basicity from 1.0 to 1.2 . In the test, the recovery rate of $\mathrm{Fe}, \mathrm{V}$, and $\mathrm{Cr}$ in iron $\left(R_{F e}\right.$, $\left.R_{V}, R_{C r}\right)$ together with the recovery rate of $\mathrm{TiO}_{2}$ in separation slag $\left(R_{\mathrm{TiO}_{2}}\right)$ is considered as the four evaluation indexes. The results including index data and morphologies of iron and separation slag are given in Table 2 and Fig. 2, respectively. The considered indexes show relatively good values, meanwhile, the surface of iron is smooth which indicates that the separation proceeds successfully. In other words, the optimization in the given range is reasonable and credible.

Table 2. Scheme and result of the orthogonal test.

\begin{tabular}{cccccccc}
\hline \multirow{2}{*}{ No } & \multicolumn{3}{c}{ Factor } & \multicolumn{4}{c}{ Results } \\
\cline { 2 - 8 } & $\mathrm{A} /{ }^{\circ} \mathrm{C}$ & $\mathrm{B} / \mathrm{min}$ & $\mathrm{C} /-$ & $R_{F F} / \%$ & $R_{V} / \%$ & $R_{\mathrm{Cr}} / \%$ & $R_{T i O_{2}} / \%$ \\
\hline 1 & 1600 & 45 & 1.0 & 99.58 & 95.13 & 89.71 & 91.61 \\
2 & 1600 & 50 & 1.1 & 99.14 & 94.82 & 87.8 & 95.91 \\
3 & 1600 & 55 & 1.2 & 99.58 & 94.96 & 90.74 & 93.97 \\
4 & 1625 & 45 & 1.1 & 99.96 & 96.37 & 92.50 & 94.74 \\
5 & 1625 & 50 & 1.2 & 97.79 & 96.89 & 91.75 & 94.29 \\
6 & 1625 & 55 & 1.0 & 98.83 & 93.16 & 87.84 & 95.55 \\
7 & 1650 & 45 & 1.2 & 99.86 & 96.27 & 90.46 & 91.89 \\
8 & 1650 & 50 & 1.0 & 99.04 & 95.67 & 90.02 & 90.91 \\
9 & 1650 & 55 & 1.1 & 98.28 & 97.22 & 94.38 & 93.65 \\
\hline
\end{tabular}

Note: A-Melting temperature, B-Melting time, C-Basicity
The orthogonal range analysis is listed in Table 3. The change rule of HCVTMP melting separation indexes under series factor level is described in Fig. 3. These results quantitatively indicate the significance of each key process factor

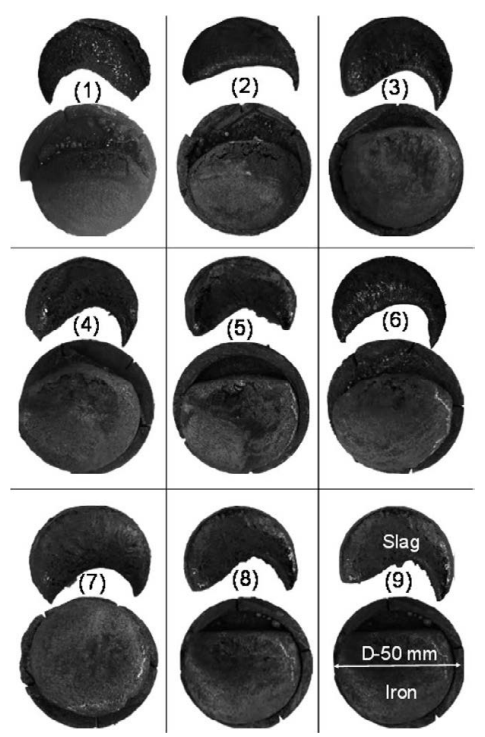

Fig. 2. Morphology of the separation iron and slag for each orthogonal test.
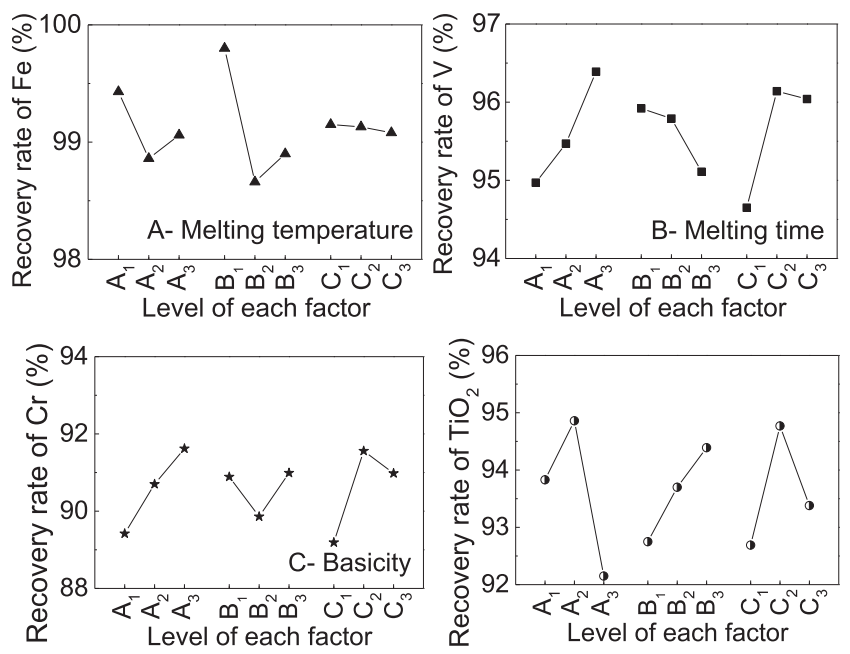

Fig. 3. Change rule of HCVTMP melting separation indexes under series factor level.

Table 3. Range analysis of orthogonal test

\begin{tabular}{|c|c|c|c|c|c|c|c|c|c|c|c|c|}
\hline \multirow{2}{*}{$\begin{array}{l}\text { Index } \\
\text { Factor }\end{array}$} & \multicolumn{3}{|c|}{$R_{F e} / \%$} & \multicolumn{3}{|c|}{$R_{V} / \%$} & \multicolumn{3}{|c|}{$R_{C r} / \%$} & \multicolumn{3}{|c|}{$R_{T_{i} O_{2} / \%}$} \\
\hline & A & B & $\mathrm{C}$ & A & B & $\mathrm{C}$ & A & B & $\mathrm{C}$ & A & B & $\mathrm{C}$ \\
\hline$k_{l}$ & 99.43 & 99.80 & 99.15 & 94.97 & 95.92 & 94.65 & 89.42 & 90.89 & 89.19 & 93.83 & 92.75 & 92.69 \\
\hline$k_{2}$ & 98.86 & 98.66 & 99.13 & 95.47 & 95.79 & 96.14 & 90.70 & 89.86 & 91.56 & 94.86 & 93.70 & 94.77 \\
\hline$k_{3}$ & 99.06 & 98.90 & 99.08 & 96.39 & 95.11 & 96.04 & 91.62 & 90.99 & 90.98 & 92.15 & 94.39 & 93.38 \\
\hline$R$ & 0.57 & 1.14 & 0.07 & 1.42 & 0.81 & 1.48 & 2.20 & 1.13 & 2.37 & 2.71 & 1.64 & 2.08 \\
\hline Significance & \multicolumn{3}{|c|}{$R_{B}>R_{A}>R_{C}$} & \multicolumn{3}{|c|}{$R_{C}>R_{A}>R_{B}$} & \multicolumn{3}{|c|}{$R_{C}>R_{A}>R_{B}$} & \multicolumn{3}{|c|}{$R_{A}>R_{C}>R_{B}$} \\
\hline Optimum & $\mathrm{A}_{1}$ & $\mathrm{~B}_{1}$ & $\mathrm{C}_{1}$ & $\mathrm{~A}_{3}$ & $\mathrm{~B}_{1}$ & $\mathrm{C}_{2}$ & $\mathrm{~A}_{3}$ & $\mathrm{~B}_{3}$ & $\mathrm{C}_{3}$ & $\mathrm{~A}_{2}$ & $\mathrm{~B}_{3}$ & $\mathrm{C}_{2}$ \\
\hline
\end{tabular}

Note: A-Melting temperature, B-Melting time, C-Basicity 
on the HCVTMP melting separation indexes and the optimal conditions for different factors. The factor affecting $R_{F e}$ in descending order of significance is melting time $>$ melting temperature > basicity; the optimal condition for better $R_{F e}$ is $1600^{\circ} \mathrm{C}, 45 \mathrm{~min}$, and basicity of 1.0 . The order of each factor affecting $R_{V}$ is basicity $>$ melting temperature $>$ melting time; the optimal condition for higher $R_{V}$ is $1650^{\circ} \mathrm{C}, 45$ min, and basicity of 1.1. The order of each factor affecting $R_{C r}$ is basicity $>$ melting temperature $>$ melting time; the optimal condition for higher $R_{C r}$ is $1650^{\circ} \mathrm{C}, 55 \mathrm{~min}$, and basicity of 1.1. The order of each factor affecting $R_{\mathrm{TiO}_{2}}$ is melting temperature $>$ basicity $>$ melting time; the optimal condition for higher $R_{\mathrm{TiO}_{2}}$ is $1625^{\circ} \mathrm{C}, 55 \mathrm{~min}$, and basicity of 1.1 .

\subsection{Optimization of HCVTMP Melting Separation by Synthetic Weighted Scoring Method}

The multi-index synthetic weighted scoring method is used to determine the optimal HCVTMP melting separation parameters. Considering the importance of subjective cognizance and making the most use of objective test results, the weight value of indexes should accomplish the unification of the subject and object, then the scoring is objective, true, and effective.

\subsubsection{Determination of Standardized Evaluation Matrix}

In a multi-index test, there are $n$ schemes marked as $\boldsymbol{I}=$ $\{1,2,3, \ldots, n\}$ and $m$ indexes marked as $\boldsymbol{J}=\{1,2, \ldots, m\}$. The corresponding experimental data are $x_{i j}(i=1,2,3, \ldots$, $n ; j=1,2,3, \ldots, m)$ which make up an evaluation matrix marked as $\boldsymbol{X}=\left(x_{i j}\right)_{n \times m}$.

To unify the tendency requirement of each index and remove its incommensurability, the evaluation matrix should be standardized. Assuming, $\boldsymbol{I}_{1}=\{$ the indexes with "the lower, the better" $\}, I_{2}=$ the indexes with "the higher, the better" $\}, \boldsymbol{I}_{3}=$ the indexes with a stable and desired value $\}, \boldsymbol{I}_{1} \cup \boldsymbol{I}_{2} \cup \boldsymbol{I}_{3}=\boldsymbol{I}$. When the judgment standard of the weight scoring value is "the lower, the better" or "the high, the better", the different forms of $y_{i j}$ are given as Eqs. (3) and (4), respectively. Where, $x_{j}^{*}\left(j \in I_{3}\right)$ is the desired value for index; $x_{\text {jmax }}=\max _{1 \leq i \leq n}\left\{x_{i j}\right\}$.

For unifying the index's magnitude order and removing its dimension, the $z_{i j}$ is commanded as Eq. (5). Where, $y_{\text {jmin }}=\min \left\{y_{i j} \mid i=1,2,3 \ldots, n\right\} ; y_{\text {jmax }}=\max \left\{y_{i j} \mid i=1,2\right.$, $3 \ldots, n\} . \boldsymbol{Z}=\left(z_{i j}\right)$ is the final standardized evaluation matrix.

$$
\begin{gathered}
y_{i j}=\left\{\begin{array}{ll}
x_{i j} & j \in \boldsymbol{I}_{1} \\
x_{j \max }-x_{i j} & j \in \boldsymbol{I}_{2} \\
-\left|x_{i j}-x_{j}^{*}\right| & j \in \boldsymbol{I}_{3}
\end{array}\right\} \ldots \ldots . . \\
y_{i j}=\left\{\begin{array}{ll}
x_{j \max }-x_{i j} & j \in \boldsymbol{I}_{1} \\
x_{i j} & j \in \boldsymbol{I}_{2} \\
-\left|x_{i j}-x_{j}^{*}\right| & j \in \boldsymbol{I}_{3}
\end{array}\right\} \ldots \ldots . . \\
z_{i j}=100 \times\left(y_{i j}-y_{j \min }\right) /\left(y_{j \max }-y_{j \min }\right), \\
i=1,2,3 \ldots, n ; j=1,2,3 \ldots, m
\end{gathered}
$$

In the present HCVTMP melting separation process, the recovery rates of $\mathrm{Fe}, \mathrm{V}, \mathrm{Cr}$, and $\mathrm{TiO}_{2}$ are the four evaluation indexes which are all expected to be higher as much as possible. The evaluation matrix $\boldsymbol{X}=\left(x_{i j}\right)$ can be gained from experimental data listed in Table 2. According to the judgment standard that "the higher, the better" as Eq. (4), the final standardized evaluation matrix $\boldsymbol{Z}\left(z_{i j}\right)$ is obtained.

$\boldsymbol{X}=\left(x_{94}\right)=\left[\begin{array}{cccc}99.58 & 95.13 & 89.71 & 91.61 \\ 99.14 & 94.82 & 87.80 & 95.91 \\ 99.58 & 94.96 & 90.74 & 93.97 \\ 99.96 & 96.37 & 92.50 & 94.74 \\ 97.79 & 96.89 & 91.75 & 94.29 \\ 98.83 & 93.16 & 87.84 & 95.55 \\ 99.86 & 96.27 & 90.46 & 91.89 \\ 99.04 & 95.67 & 90.02 & 90.91 \\ 98.28 & 97.22 & 94.38 & 93.65\end{array}\right]$

3.2.2. Determination of Synthetic Weight of Each Index

The HCVT used in the work is imported from Russia, and it is a remnant after the iron ore beneficiation titanium. The content of $\mathrm{TiO}_{2}$ is relatively low. On the premise of ensuring the relatively high recovery of $\mathrm{Ti}$, the main aim for comprehensively utilizing this HCVT is to improve the recoveries of $\mathrm{Fe}, \mathrm{V}$ and $\mathrm{Cr}$ as much as possible. As a result, firstly based on the previous experience and requirement during the optimization of HCVTMP melting separation process, the expert investigating method is used to obtain the subjective weight for each index. ${ }^{15,16)}$ The subjective weight of $\mathrm{Fe}, \mathrm{V}, \mathrm{Cr}$, and $\mathrm{TiO}_{2}$ recovery rate in this work is $\alpha_{1}=0.3, \alpha_{2}=0.3, \alpha_{3}=0.3$, and $\alpha_{4}=0.1$, respectively. It means that the matrix of subjective weight is $\alpha=[0.3$, $0.3,0.3,0.1]^{T}$.

Secondly, from the entropy evaluation method, ${ }^{16,22)}$ $\beta=\left(1-h_{j}\right) / \sum_{k=1}^{m}\left(1-h_{k}\right)(j=1,2,3, \ldots, m ; k \leq j)$, where, $h_{j}=(\ln n)^{-1} \sum_{i=1}^{k=1} p_{i j} \ln p_{i j}$, and $p_{i j}=z_{i j} / \sum_{i=1}^{n} z_{i j}$. Notes, $p_{i j} \ln p_{i j}=$ $0(i=1,2,3, \ldots, n ; j=1,2,3, \ldots, m)$ when $p_{i j}=0$. Then the objective weights are also given as $\beta=[0.31,0.27$, $0.24,0.18]^{T}$.

Finally, in order to achieve the unity of the subjective and objective, the optimization decision model is established as Eq. (6). Where, $\mu(0 \leq \mu \leq 1)$ is the inclination coefficient that reflects the preference degree for the subjective and objective weights. Here, $\mu=0.5$. The final synthetic weight for each index is obtained as $\boldsymbol{w}=[0.30,0.28,0.27,0.14]^{T}$. 


$$
\begin{aligned}
& \min F(w)=\sum_{i=1}^{n} \sum_{j=1}^{m}\left\{\mu\left[\left(w_{j}-\alpha_{j}\right) z_{i j}\right]^{2}+(1-\mu)\left[\left(w_{j}-\beta_{j}\right) z_{i j}\right]^{2}\right\} \\
& s t\left\{\begin{array}{l}
\sum_{j=1}^{m} w_{j}=1 \\
w_{j} \geq 0, j=1,2, \ldots, m
\end{array}\right.
\end{aligned}
$$

\subsubsection{Calculation of Synthetic Weighted Score}

From the formula described as Eq. (7), the synthetic weighted score for each index is calculated as:

$\boldsymbol{f}=[94.53,94.40,95.09,96.19,95.41,93.79,95.18$, $94.50,96.27]^{T}$

$$
f_{i}=\sum_{i=1}^{n} w_{j} z_{i j}(i=1,2, \ldots, n, j=1,2, \ldots, m)
$$

\subsubsection{Single Index Analysis Evaluation}

Subsequently, the optimization of HCVTMP melting separation is investigated by the single index analysis evaluation and the results are listed in Table 4. Through the whole multi-index synthetic weighted scoring method, the optimal HCVTMP melting separation parameters are obtained as follows: a melting temperature of $1650^{\circ} \mathrm{C}$, a melting time of $45 \mathrm{~min}$, and a basicity of 1.1 . The basicity most strongly affects the HCVTMP melting separation, followed successively by the melting temperature and melting time. In addition, the effect of inclination coefficient $(\mu)$ on the optimization is also discussed in Table 5. All the significance order and optimum are the same under any inclination coefficient. The basicity still has the most significant effect on HCVTMP melting separation.

The HCVTMP melting separation is applied under the optimal conditions. The recovery amount and compositions

\begin{tabular}{|c|c|c|c|c|c|c|c|c|}
\hline \multirow{2}{*}{ No } & \multicolumn{3}{|c|}{ Index } & \multicolumn{4}{|c|}{ Factor } & \multirow{2}{*}{$f$} \\
\hline & $\mathrm{A}^{*} /{ }^{\circ} \mathrm{C}$ & $\mathrm{B}^{*} / \mathrm{min}$ & $\mathrm{C}^{*} /-$ & $R_{F e} / \%$ & $R_{V} / \%$ & $R_{C r} / \%$ & $R_{\mathrm{TiO}_{2} / \%}$ & \\
\hline 1 & 1600 & 45 & 1.0 & 99.58 & 95.13 & 89.71 & 91.61 & 94.53 \\
\hline 2 & 1600 & 50 & 1.1 & 99.14 & 94.82 & 87.80 & 95.91 & 94.40 \\
\hline 3 & 1600 & 55 & 1.2 & 99.58 & 94.96 & 90.74 & 93.97 & 95.09 \\
\hline 4 & 1625 & 45 & 1.1 & 99.96 & 96.37 & 92.50 & 94.74 & 96.19 \\
\hline 5 & 1625 & 50 & 1.2 & 97.79 & 96.89 & 91.75 & 94.29 & 95.41 \\
\hline 6 & 1625 & 55 & 1.0 & 98.83 & 93.16 & 87.84 & 95.55 & 93.79 \\
\hline 7 & 1650 & 45 & 1.2 & 99.86 & 96.27 & 90.46 & 91.89 & 95.18 \\
\hline 8 & 1650 & 50 & 1.0 & 99.04 & 95.67 & 90.02 & 90.91 & 94.50 \\
\hline 9 & 1650 & 55 & 1.1 & 98.28 & 97.22 & 94.38 & 93.65 & 96.27 \\
\hline $\mathrm{K}_{1}$ & 93.21 & 94.51 & 93.09 & \multicolumn{5}{|c|}{$w_{1}=0.30, w_{2}=0.28, w_{3}=0.27, w_{4}=0.14$} \\
\hline $\mathrm{K}_{2}$ & 94.53 & 93.98 & 94.95 & \multicolumn{5}{|c|}{ Significance $\mathrm{C}>\mathrm{A}>\mathrm{B}$} \\
\hline $\mathrm{K}_{3}$ & 94.91 & 94.15 & 94.61 & \multicolumn{5}{|c|}{ Level $C_{2} A_{3} B_{1}$} \\
\hline $\mathrm{R}$ & 1.70 & 0.53 & 1.86 & \multicolumn{5}{|c|}{ Optimum $\mathrm{A}_{3} \quad \mathrm{~B}_{1} \mathrm{C}_{2}$} \\
\hline
\end{tabular}

Table 4. Result and conclusion of the optimization for HCVTMP melting separation.

Note: A-Melting temperature, B-Melting time, C-Basicity of slag and metal are listed in Table 6. The mass fraction of $\mathrm{Fe}, \mathrm{V}, \mathrm{Cr}$, and $\mathrm{TiO}_{2}$ reach $94.16 \%, 0.94 \%, 0.76 \%$, and $38.21 \%$, respectively. And the recovery of $\mathrm{Fe}, \mathrm{V}, \mathrm{Cr}$, and $\mathrm{TiO}_{2}$ is high to $99.87 \%, 98.26 \%, 95.32 \%$, and $95.04 \%$, respectively. Compared with the single index test results, ${ }^{21}$ all the recoveries and mass fraction are improved obviously. The cross section of separation slag and iron (rapidly cooled down in argon atmosphere) under the optimum are analyzed by SEM-EDS, shown in Fig. 4. In (a) and (c), the

Table 5. Optimal parameters under different inclination coefficient $\mu$.

\begin{tabular}{ccccccc}
\hline & \multicolumn{5}{c}{ Synthetic weight } & \\
\cline { 2 - 5 } & $w_{1}$ & $w_{2}$ & $w_{3}$ & $w_{4}$ & & \\
\hline 0 & 0.31 & 0.27 & 0.24 & 0.18 & $\mathrm{C}>\mathrm{A}>\mathrm{B}$ & $\mathrm{A}_{3} \mathrm{~B}_{1} \mathrm{C}_{2}$ \\
0.2 & 0.31 & 0.27 & 0.25 & 0.17 & $\mathrm{C}>\mathrm{A}>\mathrm{B}$ & $\mathrm{A}_{3} \mathrm{~B}_{1} \mathrm{C}_{2}$ \\
0.4 & 0.30 & 0.28 & 0.26 & 0.15 & $\mathrm{C}>\mathrm{A}>\mathrm{B}$ & $\mathrm{A}_{3} \mathrm{~B}_{1} \mathrm{C}_{2}$ \\
0.5 & 0.30 & 0.28 & 0.27 & 0.14 & $\mathrm{C}>\mathrm{A}>\mathrm{B}$ & $\mathrm{A}_{3} \mathrm{~B}_{1} \mathrm{C}_{2}$ \\
0.6 & 0.30 & 0.29 & 0.28 & 0.13 & $\mathrm{C}>\mathrm{A}>\mathrm{B}$ & $\mathrm{A}_{3} \mathrm{~B}_{1} \mathrm{C}_{2}$ \\
0.8 & 0.30 & 0.30 & 0.29 & 0.12 & $\mathrm{C}>\mathrm{A}>\mathrm{B}$ & $\mathrm{A}_{3} \mathrm{~B}_{1} \mathrm{C}_{2}$ \\
1.0 & 0.30 & 0.30 & 0.30 & 0.10 & $\mathrm{C}>\mathrm{A}>\mathrm{B}$ & $\mathrm{A}_{3} \mathrm{~B}_{1} \mathrm{C}_{2}$ \\
\hline
\end{tabular}

Note: A-Melting temperature, B-Melting time, C-Basicity

Table 6. Recovery amount and compositions of slag and metal under the optimal conditions.

\begin{tabular}{lccccccccc}
\hline$M_{I} / \mathrm{g}$ & \multicolumn{7}{c}{$C_{I} / \%$} \\
\hline \multirow{2}{*}{81.26} & $\mathrm{TFe}$ & $\mathrm{V}$ & $\mathrm{Cr}$ & $\mathrm{Ti}$ & $\mathrm{Si}$ & $\mathrm{S}$ & - & - \\
\cline { 2 - 9 } & 94.16 & 0.94 & 0.76 & 0.340 & 0.034 & 0.007 & - & - \\
\hline \multirow{2}{*}{$M_{S} / \mathrm{g}$} & \multicolumn{7}{c}{$C_{S} / \%$} \\
\hline \multirow{2}{*}{23.05} & $\mathrm{TFe}$ & $\mathrm{V}$ & $\mathrm{Cr}$ & $\mathrm{TiO}_{2}$ & $\mathrm{CaO}$ & $\mathrm{SiO}_{2}$ & $\mathrm{MgO}$ & $\mathrm{Al}_{2} \mathrm{O}_{3}$ \\
\cline { 2 - 9 } & 0.45 & 0.058 & 0.132 & 38.21 & 21.19 & 13.44 & 6.72 & 18.55
\end{tabular}

Note: $M_{P}, M_{I}, M_{S}$-Mass of HCVTMP, Iron, Slag; $C_{I}, C_{S^{-}}$Composition of iron, slag
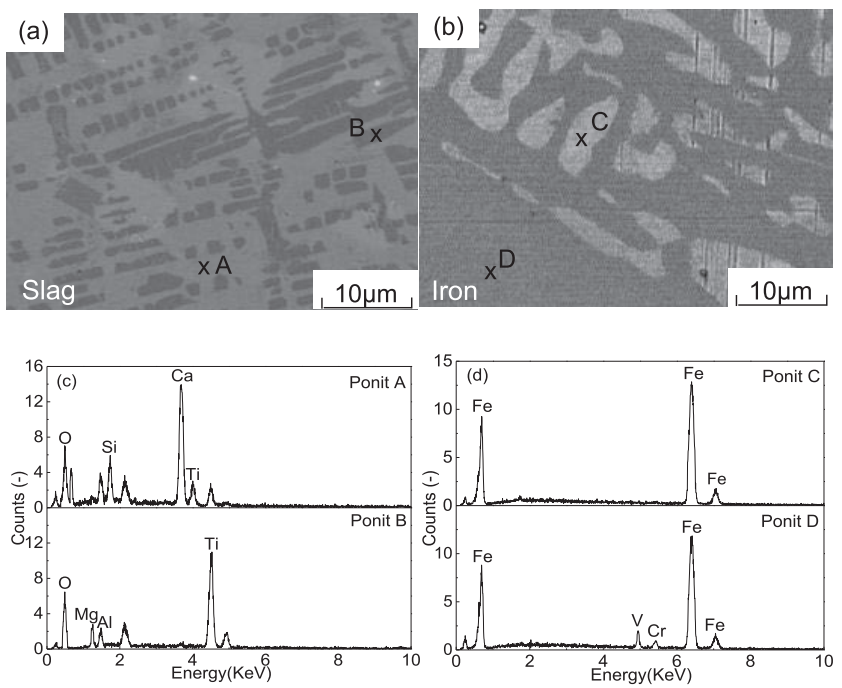

Fig. 4. SEM-EDS analyses of the separation slag and iron under optimal conditions. 
two phases that the light gray (Point A) has more calcium while the dark gray (Point B) contains more titanium. Seen from (b) and (d), there are also two phases in iron, the bright white of pure metallic iron (Point $\mathrm{C}$ ) and the gray white of metallic iron containing $\mathrm{V}$ and $\mathrm{Cr}$ (Point D).

\subsection{Function Mechanism of Basicity on the HCVTMP Melting Separation}

From the optimization by multi-index synthetic weighted scoring method, it is evident that basicity is really the most significant factor that affects HCVTMP melting separation, it is quite necessary to further confirm its function mechanism. Therefore the detailed single index tests are supplemented and shown in Fig. 5. When holding the HCVTMP original basicity of 0.13 , the melting can't be achieved at all. Slightly increasing basicity to 0.60 , the relatively big iron is gathered at the bottom of crucible, but the separation is still not done successfully. So the data under the two basicity are inaccurate and not given. Further increasing basicity continuously, all the indexes show the tendency of first increase and then decrease, and have the highest value at the basicity of 1.10 .

Effect of basicity on the thermodynamic equilibrium of HCVTMP melting is evaluated by the Equilib module in FACTSAGE 7.0 package. The databases including FactPS, FToxid, FTstel, and $\mathrm{Fe}_{2} \mathrm{VO}_{4}{ }^{23)}$ (established by author) are applied. The system pressure is $1.01 \times 10^{5} \mathrm{~Pa}$, and the initial atmosphere is in Ar. The possible products are considered: liquid metal, metal carbide, metal oxide, liquid carbon, solid carbon, spinel, anosovite, monoxide, clinopyroxene, wollastonite, anorthite, cordierite, melilite, olivine, mullite, corundum, pseudobrookite, ulvaespinel, rutile, and perovskite etc. $100 \mathrm{~g}$ HCVTMP samples with $\mathrm{C}, \mathrm{CaO}$, and $\mathrm{CaF}_{2}$ are
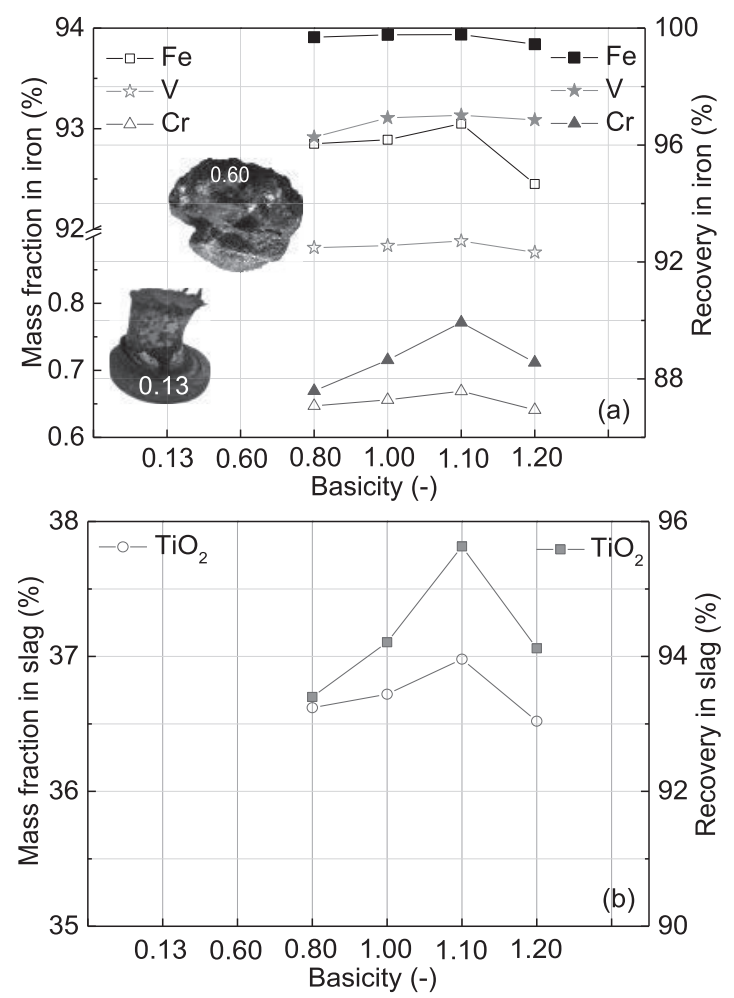

Fig. 5. Melting separation indexes in iron (a) and separation slag (b) under different basicity. analyzed with the temperature range of $1000-1700^{\circ} \mathrm{C}$ and the basicity range of $0.13-1.20$. The possible liquid products including $\mathrm{Fe}(\mathrm{l}), \mathrm{V}$ (1), $\mathrm{Cr}$ (1), and Ti (l) are emphasized in Fig. 6. As increased basicity, the amount of $\mathrm{Ti}$ (1) has a slight decrease which is good for titanium oxide enrichment in slag. Beyond that, the major liquids of $\mathrm{Fe}(\mathrm{l}), \mathrm{V}(\mathrm{Cr})$, and $\mathrm{V}$ (l) are almost the same despite of the obvious increase of basicity. However, the result from experiment (Fig. 5) shows that all the indexes are sensitive to basicity. It is speculated that the influences of basicity on melting separation kinetic are greater than thermodynamic.

Viscosity of the slag formed in HCVTMP melting separation with different basicity is calculated by Viscosity module in FACTSAGE 7.0 package. The Melts database is applied. The evaluated temperature range is $1350-1700^{\circ} \mathrm{C}$. The viscosity calculation results are described in Fig. 7. It's obvious that the viscosity decreases gradually as increased basicity. Generally, the slag with a low viscosity is of great benefit to good diffusion and mass transfer due to its good fluidity. So by rising basicity, the melting separation kinetic is enhanced due to the decreasing slag viscosity, the successful separation of iron and slag is promoted.

Besides viscosity, the surface tension of slag is another key point in melting separation process for controlling various surface and interfacial phenomena. The bigger surface tension of molten slag will lead to the decreasing adhesion work between iron and slag which makes the slag difficult to
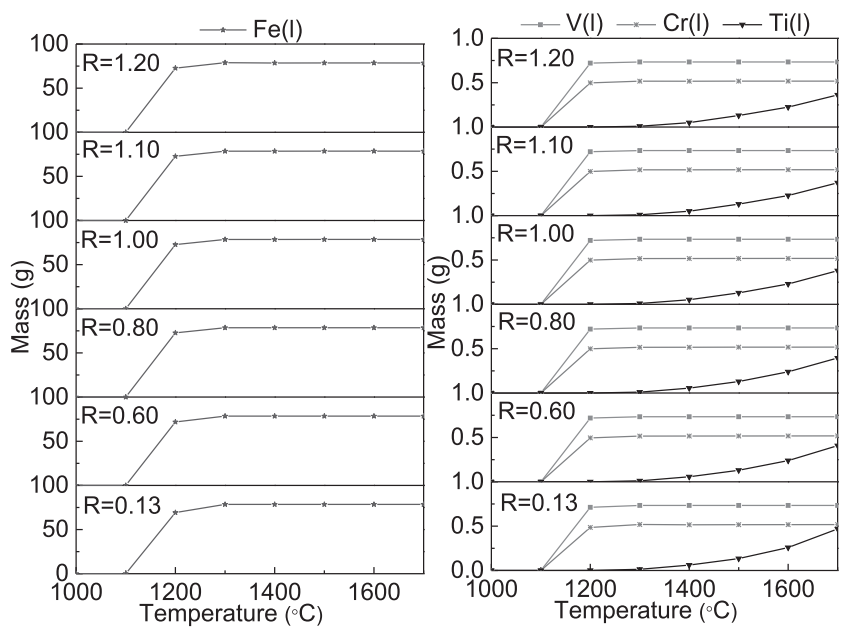

Fig. 6. Thermodynamic equilibrium analysis by FACTSAGE 7.0 package under different basicity.

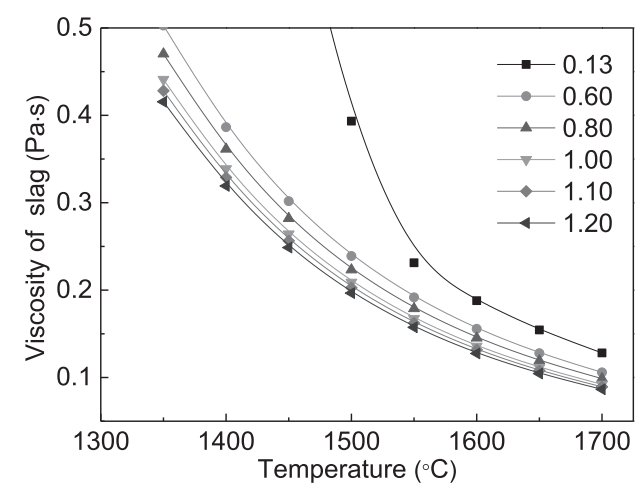

Fig. 7. Viscosity of the slag with different basicity. 
be brought to iron, and then the separation of iron and slag is improved. ${ }^{24)}$ Therefore, the effect of basicity on HCVTMP melting separation is considered from the aspect of slag surface tension. According to the prediction model derived by Tanaka et $a .^{25}$ ) and the research on the surface tension of molten blast furnace slag bearing $\mathrm{TiO}_{2},{ }^{26)}$ the surface tension of HCVTMP melting separation slag $\left(\mathrm{CaO}-\mathrm{SiO}_{2}-\right.$ $\left.\mathrm{MgO}-\mathrm{Al}_{2} \mathrm{O}_{3}-\mathrm{TiO}_{2}-\mathrm{CaF}_{2}\right)$ is evaluated based on the Bulter's equation. The surface tension is calculated by Eqs. (8)-(10).

$$
\begin{gathered}
\sigma=\sigma_{i}^{\text {Pure }}+\frac{R T}{A_{i}} \ln \frac{M_{i}^{\text {Surf }}}{M_{i}^{\text {Bulk }}} \\
A_{i}=N_{0}^{1 / 3} \cdot V_{i}^{2 / 3} \ldots \ldots \ldots \\
M_{i}^{P}=\frac{\frac{R_{i}^{\text {Cation }}}{R_{i}^{\text {Anion }}} \cdot N_{i}^{P}}{\sum_{i} \frac{R_{i}^{\text {Cation }}}{R_{i}^{\text {Anion }}} \cdot N_{i}^{P}} \ldots
\end{gathered}
$$

Where, $\sigma$ is the surface tension of molten slag, $\mathrm{mN} / \mathrm{m}$; $i$ refers to the following components: $\mathrm{CaO}, \mathrm{SiO}_{2}, \mathrm{MgO}$, $\mathrm{Al}_{2} \mathrm{O}_{3}, \mathrm{TiO}_{2}, \mathrm{CaF}_{2} ; \sigma_{i}^{\text {Pure }}$ is the surface tension of pure molten component $i, \mathrm{mN} / \mathrm{m} ; R$ is the gas constant, $-; T$ is the absolute temperature, $\mathrm{K} ; A_{i}$ is the molar surface area in a mono layer of pure molten component $i, \mathrm{~m}^{2} ; N_{0}$ is Avogadro number, -; $V_{i}$ is the molar volume of pure molten component $i, \mathrm{~m}^{3} / \mathrm{mol} ; R_{i}^{\text {Cation }}$ and $R_{i}^{\text {Anion }}$ is the radium of cation and anion respectively, $\mathrm{m} ; N_{i}^{P}$ is the mole fraction of component $i$ in phase $P,-; P$ is Surf (surface) or Bulk (bulk). In addition, $\mathrm{SO}_{4}{ }^{4-}$ is thought to be the minimum anionic unit in $\mathrm{SiO}_{2}$ and the ratio of $R_{\mathrm{Si}^{4+}}$ to $R_{\mathrm{SiO}_{4}^{4-}}$ is $0.5 .{ }^{27,28)}$

\begin{tabular}{|c|c|c|}
\hline \multirow{2}{*}{ Oxide } & \multicolumn{2}{|c|}{ Radii of ions/Å } \\
\hline & Cation & Anion \\
\hline $\mathrm{CaO}$ & $\mathrm{Ca}^{2+} 0.42$ & $\mathrm{O}^{2-} 1.44$ \\
\hline $\mathrm{SiO}_{2}$ & $\mathrm{Si}^{4+} 0.42$ & $\mathrm{SiO}_{4}{ }^{4-} 0.84$ \\
\hline $\mathrm{MgO}$ & $\mathrm{Mg}^{2+} 0.66$ & $\mathrm{O}^{2-} 1.44$ \\
\hline $\mathrm{Al}_{2} \mathrm{O}_{3}$ & $\mathrm{Al}^{3+} 0.51$ & $\mathrm{O}^{2-} 1.44$ \\
\hline $\mathrm{TiO}_{2}$ & $\mathrm{Ti}^{4+} 0.61$ & $\mathrm{O}^{2-} 1.44$ \\
\hline $\mathrm{CaF}_{2}$ & $\mathrm{Ca}^{2+} 0.99$ & $\mathrm{~F}^{-} 1.33$ \\
\hline
\end{tabular}

The data including the ionic radii together with the

Table 7. Radii of cation and anionic.

Table 8. Temperature dependences of surface tension and molar volume of pure oxide.

\begin{tabular}{ccc}
\hline Oxide & Surface tension $/(\mathrm{mN} / \mathrm{m})$ & Molar volume $/\left(\mathrm{m}^{3} / \mathrm{mol}\right)$ \\
\hline $\mathrm{CaO}$ & $791-0.0935 \cdot T$ & $20.7 \cdot\left[1+10^{-4} \cdot(T-1773)\right] \cdot 10^{-6}$ \\
$\mathrm{SiO}_{2}$ & $243.2+0.031 \cdot T$ & $27.516 \cdot\left[1+10^{-4} \cdot(T-1773)\right] \cdot 10^{-6}$ \\
$\mathrm{MgO}$ & $1770-0.636 \cdot T$ & $16.1 \cdot\left[1+10^{-4} \cdot(T-1773)\right] \cdot 10^{-6}$ \\
$\mathrm{Al}_{2} \mathrm{O}_{3}$ & $1024-0.177 \cdot T$ & $28.3 \cdot\left[1+10^{-4} \cdot(T-1773)\right] \cdot 10^{-6}$ \\
$\mathrm{TiO}_{2}$ & $1384.3-0.6254 \cdot T$ & $22.2 \cdot\left[1-4.689 \cdot 10^{-5} \cdot(T-1023)\right] \cdot 10^{-6}$ \\
$\mathrm{CaF}_{2}$ & $1604.6-0.72 \cdot T$ & $31.3 \cdot\left[1+10^{-4} \cdot(T-1773)\right] \cdot 10^{-6}$ \\
\hline
\end{tabular}

temperature dependences of molar volume and surface tension for pure component used in the present evaluation are obtained from previous works ${ }^{26-31)}$ and listed in Tables 6 and 7 . The calculated surface tension with different basicity at $1650^{\circ} \mathrm{C}$ is given in Table 8. Meanwhile, the detection test is carried out by using RTW-10 melt physical property comprehensive testing instrument (deigned by Northeastern University, CHINA), and the data is also added into Fig. 8. The calculated values based on the present model are in good agreement with the experimental. As basicity increased, the surface tension goes up resulting in decreasing adhesion work between iron and slag, then the separation of iron and slag is enhanced and all the indexes are improved.

The metal-separation temperature usually depends on the slag melting temperature. The effects of basicity on slag initial melting temperature and slag melting temperature are evaluated by Equilib module in FACTSAGE 7.0 package and presented in Fig. 9. The evaluated basicity range is $0.13-1.20$. When calculating the slag initial melting temperature, the FToxid-Slag A is set as "F" (Formation target phase). And the FToxid-Slag A is set as "P" (Precipitate target phase) if calculating slag melting temperature. The other calculation conditions are the same to the conditions of Fig. 6 . When the basicity rising from the original $(0.13)$ to 0.60 , it is obvious that the initial melting temperature has a slight decrease but the slag melting temperature dramatically decreases from $1536^{\circ} \mathrm{C}$ to $1353^{\circ} \mathrm{C}$ accordingly. That is a pivotal reason why the HCVTMP melting separation can't be achieved successfully with the basicity below 0.6 . Further increasing basicity, the slag initial melting tem-

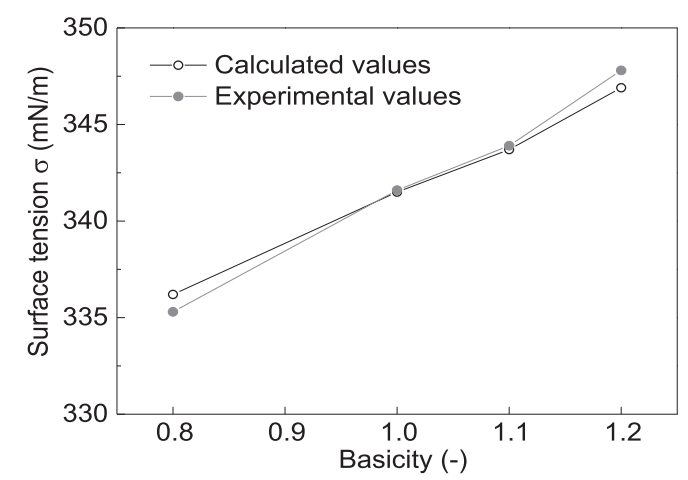

Fig. 8. Effect of basicity on the 6-component slag surface tension.

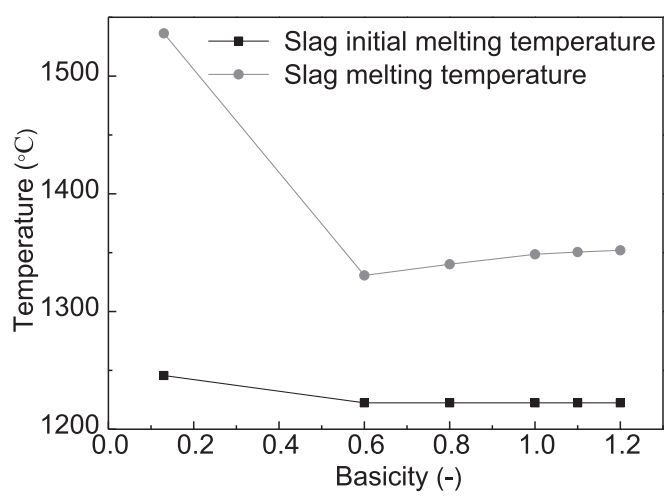

Fig. 9. Effect of basicity on initial melting separation temperature and melting temperature of the slag. 

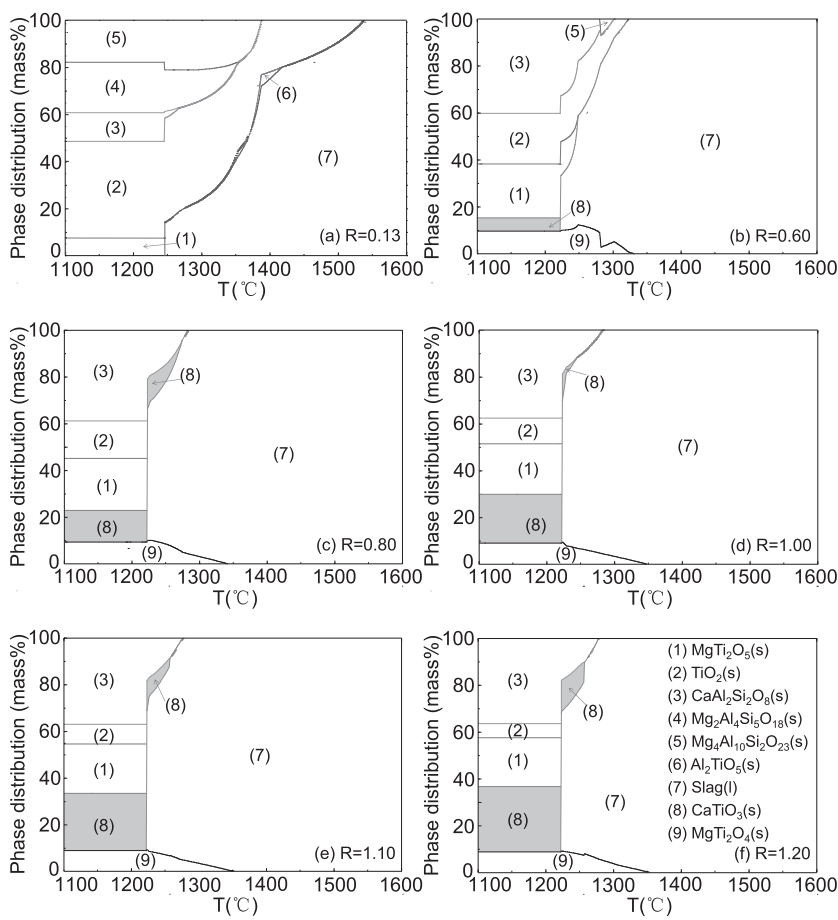

Fig. 10. Temperature dependence of equilibrium phase fraction in the slag with different basicity.

perature has no obvious changes. Instead, the slag melting temperature shows an increasing tendency which will bring some disadvantages to the separation of iron and slag.

To better understand the effect of basicity on HCVTMP melting separation behavior, the phase fraction changes of the slag with different basicity as a function of temperature are calculated by Equilib module in FACTSAGE 7.0 package and shown in Fig. 10. 100 g HCVTMP samples with $\mathrm{C}, \mathrm{CaO}$, and $\mathrm{CaF}_{2}$ are analyzed with the temperature range of $1100-1600^{\circ} \mathrm{C}$ and the basicity range of $0.13-1.20$. The other calculation conditions are the same to the conditions of Fig. 6. When the basicity is 0.13 (Fig. $10(\mathrm{a})$ ), $\mathrm{TiO}_{2}$ is observed to be in the forms of less anosovite $\mathrm{MgTi}_{2} \mathrm{O}_{5}$ (1) and more $\mathrm{TiO}_{2}(2)$; $\mathrm{CaO}$ is primitively combined with $\mathrm{SiO}_{2}$ and $\mathrm{Al}_{2} \mathrm{O}_{3}$ to generate anorthite $\mathrm{CaAl}_{2} \mathrm{Si}_{2} \mathrm{O}_{8}(3) ; \mathrm{Mg}$ is mainly dissolved in cordierite $\mathrm{Mg}_{2} \mathrm{Al}_{4} \mathrm{Si}_{5} \mathrm{O}_{18}$ (4) and sapphirine $\mathrm{Mg}_{4} \mathrm{Al}_{10} \mathrm{Si}_{2} \mathrm{O}_{23}$ (5); and a large amount of liquid phase slag (7) suddenly forms at around $1400^{\circ} \mathrm{C}$. Increasing basicity to 0.60 (Fig. 10 (b)), part of $\mathrm{CaO}$ is still in $\mathrm{CaAl}_{2} \mathrm{Si}_{2} \mathrm{O}_{8}$, but the excessive $\mathrm{CaO}$ is combined with $\mathrm{TiO}_{2}$ and the perovskite $\mathrm{CaTiO}_{3}(8)$ with a high point of $1960^{\circ} \mathrm{C}$ appears; $\mathrm{Mg}$ is mainly combined with about half of $\mathrm{TiO}_{2}$ to form $\mathrm{MgTi}_{2} \mathrm{O}_{5}$ and the new phase of $\mathrm{MgTi}_{2} \mathrm{O}_{4}$ is also observed; meanwhile, the temperature that much liquid phase will generate decreases substantially. Further rising the basicity (Figs. 10(c)-10(f)), the temperature generating much liquid slag has no obvious changes, but the amount of $\mathrm{CaTiO}_{3}$ increases evidently resulting in the increasing of slag melting temperature that has been shown in Fig. 9. Directly, the smooth HCVTMP melting separation is hindered by excessive basicity and all the indexes decrease more or less.

For improving the HCVTMP melting separation indexes, the controlling of slag amount is another key step. The proper more liquid slag amount can supply a relatively good environment for iron-slag melting separation.9) But

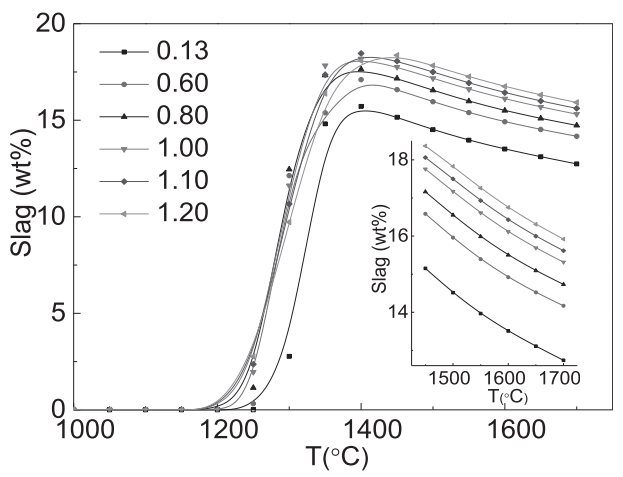

Fig. 11. Amount of slag formed during HCVTMP melting separation under different basicity.

the excessive amount slag can prevent the agglomeration of iron. Then the melting separation can't proceed perfectly. The un-agglomerate iron particle with little size may be wrapped by slag, which will decrease the recovery of Fe, $\mathrm{V}$, and $\mathrm{Cr}$ in iron. ${ }^{32)}$ As seen from the slag amount under different basicity in Fig. 11 (calculated by Equilib module in FACTSAGE 7.0 and the calculation conditions are the same to the conditions of Fig. 6), it increases with rising basicity. And from the experimental result in Fig. 5, all the indexes decrease when the basicity is further more than 1.10. Therefore, from the aspect of slag amount, HCVTMP melting separation is enhanced by rising basicity should be applied in a proper range.

According to the above analyses, increasing basicity within a certain basicity range is attributed to decreasing viscosity, increasing surface tension, decreasing slag melting point, and improving melting separation kinetic. But the excessive basicity will result in rising slag melting temperature instead and generating a large amount of slag, which are bad for improving melting separation indexes. As a result, the proper basicity for HCVTMP melting separation should be maintained at a compromised value, and for the experimental conditions, the compromised value is around 1.10.

\subsection{Process of HCVTMP Melting Separation}

The observed HCVTMP melting separation behaviors with the basicity of 1.10 are seen in Fig. 12. The camera lens is focused on the slide. They show (a) $\mathrm{Fe}-\mathrm{C}$ melt formation and $\mathrm{Fe}(\mathrm{l})$ generation for carburization, (b) slag melting initiation and slag(l) generation, (c) start of iron-slag separation (starting of aggregation of small iron droplets or slag droplets), (d) continuous aggregation and growth of iron or slag and then accomplishment of iron-slag separation (relatively big size iron droplets formation).

In order to observe the detailed behaviors of iron aggregation and growth, the camera lens is focused on the sample, and the observation results are given as Fig. 13. Firstly, in Fig. 13(a), it is spontaneous crystal nucleus formation of iron droplet at a certain point of low potential barrier, the carburization is relatively slow in this stage, with the increasing temperature, the carburization is accelerated and the amount of slag also increases, then the period for iron crystal nucleus formation is shortened and the spontaneous nucleation rate is enhanced. Secondly, in Figs. 13(b) and $13(\mathrm{c})$, it is reaction interface formation and enlarge- 


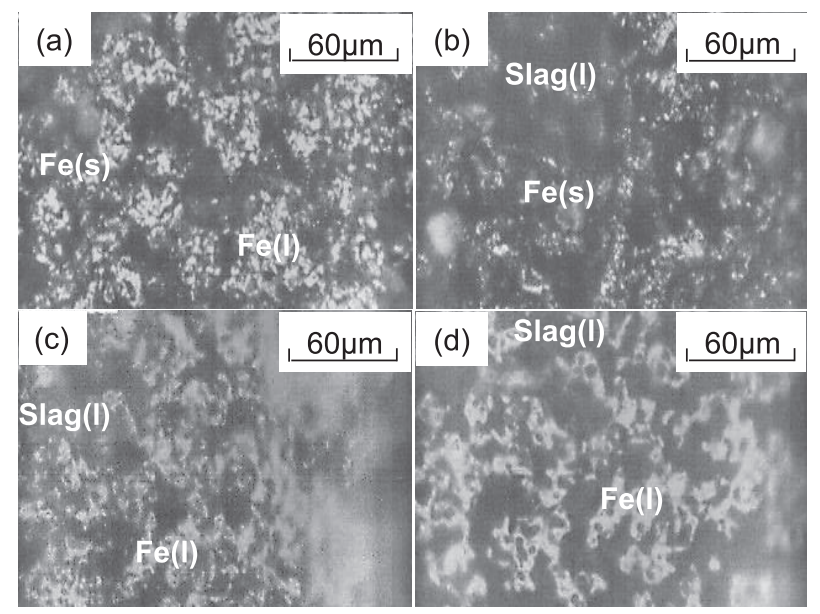

Fig. 12. In-situ CLSM observation images for HCVTMP melting separation behaviors. (a) $-1143^{\circ} \mathrm{C}$; (b) $-1358^{\circ} \mathrm{C}$; (c) $-1492^{\circ} \mathrm{C}$; (d) $-1547^{\circ} \mathrm{C}$

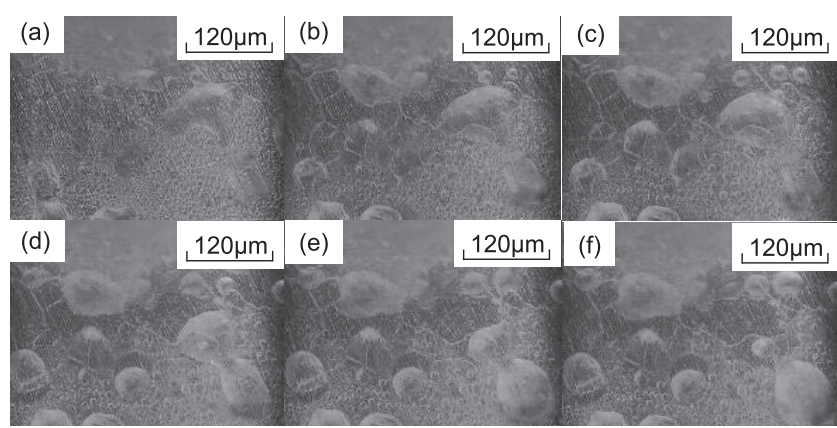

Fig. 13. In-situ CLSM observation images for metal aggregation and growth. (a) $-1518^{\circ} \mathrm{C}$; (b) $-1537^{\circ} \mathrm{C}$; (c) $-1543^{\circ} \mathrm{C}$; (d) $-1546^{\circ} \mathrm{C}$; (e) $-1548^{\circ} \mathrm{C}$; (f) $-1549^{\circ} \mathrm{C}$.

\section{(1)}

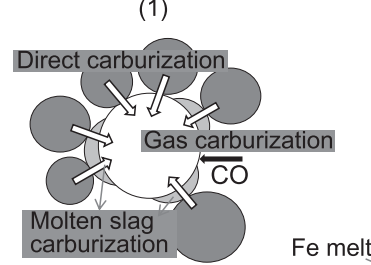

(1) Carburization phenomena

(2) Carbon and iron particle contact area change with time

(3) Fe melt aggregation and growth (a) (2)

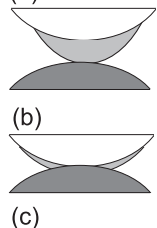

(c)

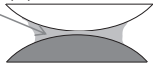

(d)
(3)

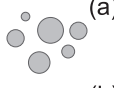

(b)

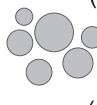

(c)

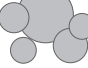

(d)
Fig. 14. Illustration of several noticeable points during HCVTMP melting separation.

ment based on the existed iron crystal nucleus, and the carburization is accelerated continuously. Thirdly, in Figs. 13(d)-13(f), it is reaction interface decrease, the reaction interfaces that formation from each crystal nucleus are assembled together, the reaction interface will decrease after the maximum generation, then iron droplets are combined and grown, the particle size of iron is becoming larger and the interfacial tension between iron and slag is bigger, and then the separation of iron and slag will be achieved.

During the HCVTMP melting separation, the excellent slag properties including less viscosity, good fluidity, and bigger surface tension are conductive to iron crystal nucleus formation, reaction interface formation and enlargement, and following reaction interface decrease and iron aggregation. Additionally, the ratio of $\sigma_{\text {metal-slag }}$ (interfacial tension between metal and slag) to $\eta_{\text {slag }}$ (slag viscosity) also has significant effects on the separation of iron and slag. If $\sigma_{\text {metal-slag }} / \eta_{\text {slag }}$ is large, ${ }^{33)}$ the separation is accomplished smoothly.

At last, the several noticeable points during HCVTMP melting separation are illustrated in Fig. 14. The carburization phenomena is given in Fig. 14(1), there are about three possibilities for iron carburization during HCVTMP melting separation, including direct carburization, gas carburization, and molten slag carburization (during melting). As the carburization reaction, the melting point of reduced iron decreases, and the diffusion together with agglomeration is accelerated, therefore, the carburization is the prerequisite for HCVTMP melting separation. In addition, the molten slag also plays an important role in HCVTMP melting separation. Kim et al. have pointed that the molten slag has a good wetting with iron but bad wetting with carbon. This good wetting and slag spreading will introduce an attractive force between iron and slag so as to make them come into contact with each other. ${ }^{34)}$ With the developing of carburization, the liquid iron will form between solid iron and carbon and its amount increases with time. These processes when molten slag carburization during melting are clearly illustrated in Fig. 14(2): (a) solid iron and carbon will come to close after molten slag formation, (b) and they contact with each other by the attractive force from good wetting between iron and molten slag, (c) then the liquid iron generates for carburization, (d) finally the contacting area between liquid iron and carbon is enlarged and the amount of liquid iron increases. Combining with the CLSM observation, the iron aggregation and growth process is simply described as Fig. 14(3), it contains (a) iron crystal nucleus formation, (b) reaction interface formation and enlargement, (c) and (d) reaction interface decrease together with iron droplets aggregation and growth.

After iron droplets of big size formation, the iron droplets sedimentate to the bottom but the slag rise to the surface for different density and surface tension, and then the separation of iron and slag is achieved naturally. It is worth noting that the reduction of the oxides bearing iron, vanadium, chromium, and titanium in HCVTMP is run through the whole deep reduction melting separation process, but the restrictive step of reduction is different during each stage.

\section{Conclusions}

(1) The optimal HCVTMP melting separation parameters are obtained by multi-index synthetic weighted scoring method and included a melting temperature of $1650^{\circ} \mathrm{C}$, a melting time of $45 \mathrm{~min}$, and a basicity of 1.10 . Under these conditions, the recoveries of $\mathrm{Fe}, \mathrm{V}, \mathrm{Cr}$, and $\mathrm{TiO}_{2}$ reach $99.87 \%, 98.26 \%, 95.32 \%$, and $95.04 \%$ respectively; the mass fraction of $\mathrm{Fe}, \mathrm{V}, \mathrm{Cr}$, and $\mathrm{TiO}_{2}$ are $94.16 \%, 0.94 \%$, $0.76 \%$, and $38.21 \%$ respectively. The basicity most strongly affects the HCVTMP melting separation, followed successively by the melting temperature and melting time. And the optimization is credible and valid.

(2) The effect of basicity on the HCVTMP melting 
separation kinetic is more considerable than thermodynamic. As increased basicity from 0.6 to 1.1 , slag viscosity decreases, surface tension increases, and melting temperature decreases, which are all attributed to smooth melting separation and improved indexes. But further increasing basicity to 1.2 , the amount of $\mathrm{CaTiO}_{3}$ increases and slag melting point rises instead, meanwhile, the amount of slag is relatively excessive, then all the HCVTMP melting separation indexes show a decrease tendency.

(3) HCVTMP melting separation process contains four key behaviors: $\mathrm{Fe}-\mathrm{C}$ melt formation and $\mathrm{Fe}(\mathrm{l})$ generation, slag melting initiation and slag(l) generation, start of ironslag separation, and continuous aggregation and growth of iron or slag and then accomplishment of iron-slag separation. As for iron aggregation and growth, it should go through iron crystal nucleus formation, reaction interface formation and enlargement, and following reaction interface decrease.

\section{Acknowledgments}

The authors are especially grateful to National Natural Science Foundation of China (Grant No. 51574067).

\section{REFERENCES}

1) L. J. Xiao: Met. Mine, (2001), No. 295, 28.

2) J. Tang, M. S. Chu and X. X. Xue: Int. J. Miner. Metall. Mater., 22 (2015), 371.

3) G. C. Du: Iron Steel Vanadium Titan., 36 (2015), 49

4) H. X. Fang, H. Y. Li and B. Xie: ISIJ Int., 52 (2012), 1958.

5) T. Hu, X. W. Lv, C. C. Bai, Z. G. Lun and G. B. Qiu: ISIJ Int., 53 (2013), 557.

6) X. W. Lv, Z. G. Lun, J. Q. Yin and C. G. Bai: ISIJ Int., 53 (2013), 1115 .

7) S. Y. Chen and M. S. Chu: Int. J. Miner. Metall. Mater., 21 (2014), 225.
8) J. Zhang, Y. H. Qi, D. L. Yan, X. L. Cheng and P. He: J. Iron Steel Res. Int., 22 (2015), 121.

9) G. Wang, Q. G. Xue, X. F. She and J. S. Wang: ISIJ Int., 55 (2015), 751.

10) C. R. Borra, S. Dwarapudi, G. Kapure, V. Tathavadkar and M. B. Denys: Ironmaking Steelmaking, 40 (2013), 443.

11) Y. P. Zhang, Z. L. Xue, Z. B. Li, J. W. Zhang, H. S. Yang and Y. S. Zhou: Iron Steel, 40 (2005), 17.

12) E. Park, S. B. Lee, O. Ostrovski, D. J. Min and C. H. Rhee: ISIJ Int., 44 (2004), 214.

13) E. Park and O. Ostrovski: ISIJ Int., 44 (2004), 999

14) Z. C. Wang, S. Y. Chen, M. S. Chu, Z. W. Han and X. X. Xue: Iron Steel Vanadium Titan., 33 (2006), 34.

15) J. M. Wu: Trans. Chin. Soc. Agric. Mach., 24 (1993), 66.

16) J. C. Tao and J. M. Wu: Syst. Eng. Theory Pract., 21 (2001), No. 8, 43.

17) Y. Zhang, J. Tang, M. S. Chu, Y. Liu, S. Y. Chen and X. X. Xue: J. Iron Steel Res. Int., 21 (2014), 144.

18) X. Wang, L. Q. Jiao, Y. Min and C. M. Yin: Chin. Tradit. Herb. Drugs, 46 (2015), 998.

19) S. B. Yao and C. Y. Yue: Syst. Eng. Electron., 27 (2005), 2047.

20) J. Tang, M. S. Chu, Z. G. Liu, S. Y. Chen and C. Feng: Proc. 18th Metallurgical Reaction Engineering, The Chinese Society for Metals, Chongqing, (2014), 104.

21) J. Tang, M. S. Chu, C. Feng, Y. T. Tang and Z. G. Liu: ISIJ Int., 56 (2016), 210.

22) F. X. Zhu and Y. H. Chen: J. Anhui Univ., 30 (2006), 4

23) Y. Wang, T. Guan, H. L. Cao, S. Q. Zhang, Z. M. Zhang and B. Xie: J. Iron Steel Res., 23 (2011), 53.

24) H. Y. Chen, Y. Wang, D. K. Li and M. Hu: Contin. Cast., 4 (2008), 42, (in Chinese).

25) T. Tanaka, K. Tomoko and A. B. Ida: ISIJ Int., 46 (2006), 400

26) Y. H. Liu, X. W. Lv, C. G. Bai and B. Yu: ISIJ Int., 54 (2014), 2154.

27) M. Hanao, T. Tanaka, M. Kawamoto and K. Takatani: ISIJ Int., 47 (2007), 935.

28) M. Nakamoto, A. Kiyose, T. Tanaka, L. Holappa and M. Hämäläinen: ISIJ Int., 47 (2007), 38.

29) R. Boni and G. Derge: J. Met., 8 (1956), 53.

30) R. Shannon: Acta Crystallogr. A, 32 (1976), 751

31) I. Sohn and D. J. Min: Steel Res. Int., 83 (2012), 611.

32) K. Ohno, M. Kaimoto, T. Maeda, K. Nishioka and M. Shimizu: ISIJ Int., 51 (2011), 1279.

33) B. Jia and B. M. Qi: J. Iron Steel Res., 31 (1996), 14.

34) H. Kim, J. G. Kim and Y. Sasaki: ISIJ Int., 50 (2010), 1099. 